\title{
EFFECT OF BOTTOM LATERAL BRACINGS ON THE BEHAVIOUR OF COMPOSITE STEEL-CONCRETE BRIDGES CURVED IN PLAN
}

\author{
Mohamed Abdel-Basset Abdo \\ Lecturer, Civil Engineering Department, Faculty of Engineering, Assiut \\ University, Assiut, Egypt.
}

(Received August 5, 2006 Accepted August 31, 2006)

\begin{abstract}
The present study is concerned with the effect of the presence of bottom lateral bracing systems on the behaviour of horizontally curved composite bridges. A careful numerical study is carried out by using the finite element method in the elastic range of loading. Shoring is assumed to be used during construction and the system is provided with cross frames. The present study includes tangential stresses, warping-tobending stress ratio, vertical displacements and radial displacements through the inner edge, middle and outer edge of the bottom flange along the span of the critical outside girder. Also, the maximum axial forces in bracing members for the most effective type are studied. Based on the numerical results, it is shown that the presence of bottom lateral bracings in curved composite bridge results in significant reduction of not only bending and warping stresses but also vertical and radial displacements as well as torsional angle of bottom flanges. The reduction in stresses of curved bridges due to the presence of lateral bracings may exceed $25 \%$ of the stresses obtained using cross frames only and the reduction in stresses is more pronounced for small radii of curvatures. So, lateral bracings can be used effectively in strengthening of existing bridges or to decrease the cross sectional area of new curved composite bridges. Also, the results show that the most effective pattern of lateral bracings is that which consists of X-bracings in all bays. However, the pattern of bracing which consists of X-bracings in end panels only give the greatest stresses and displacements of all of the studied reinforcement patterns. Furthermore, for high degree of curvature, the stresses in bracing members should be checked since they are subjected to large stresses due to curvature in addition to those due to wind loads.
\end{abstract}

KEYWORDS: Lateral bracings, composite steel-concrete girders, degree of curvature, warping and bending stresses, displacements.

\section{INTRODUCTION}

Composite construction is used extensively in modern buildings and highway bridges all over the world. The floor slab in composite construction acts not only as a slab for resisting the live loads but also as an integral part of the beam. It actually 
serves as a large cover plate for the upper flange of the steel beam, appreciably increasing beam's strength. Indeed, composite sections have greater stiffness than noncomposite sections and they have smaller deflections. The advantages of composite construction are: (1) saving in weight of steel between $30 \%$ and $50 \%$; (2) on a static ultimate load basis, an increase in the overload capacity over that of a non-composite beam; and (3) for a given load, a reduction in construction depth with consequent saving in embankment costs for bridges or storey height in buildings, [1]. The necessary stiffness for a composite bridge structure is satisfied by increasing the slab thickness and enlarging the steel beam cross section. Indeed, these improvements of girder stiffness are effective for a straight girder bridge.

In some structures such as balconies, highway bridges and interchanges in large urban area, I-girders curved in plan are frequently employed. These curved girders are subjected to large torsional loads. So, it is necessary to reinforce them to eliminate the torsional stresses and displacements. The reinforcement may be achieved using cross frames or cross frames in addition to lateral bracing system. Usually, a series of cross frames act together with the longitudinal beams or girders to form a system that behaves as a unit. On the other hand, using lateral bracings not only transmits the wind loads to substructure but also increases the torsional stiffness of the bridge since the behaviour gravitates towards that of a multi-cell box section. Indeed, in straight right-angled bridges, cross frames and lateral bracings act as secondary members in maintaining structural integrity. However, in horizontally curved and skewed bridges, the interaction of bending and torsion causes these components to become major load-carrying elements (primary members), [2].

Numerous works have been published concerning the behaviour of horizontally curved composite steel-concrete girders, e.g., [3] and [4]. Also, many researchers have investigated the effect of cross frames on the behaviour of horizontally curved bridges, e.g., [5]-[7]. Davidson et al. [8] recommended using two equations for the preliminary design of cross frame spacing for curved I-girder bridges for non-composite dead loads. Also, Abdo and Abul-Wafa [9] recommended two equations for the preliminary design of cross frame spacing for curved I-girder bridges constructed with shoring taking into account the stiffness of cross frames. Hirasawa et al. [10] studied experimentally and analytically the effect of lateral bracings on small test specimen of a two girder bridge. They concluded that the lateral bracings enable the bridge to improve its torsional stiffness and that some arranging patterns of lateral bracings have great effects on displacements despite using a small number of them. ElMezaini et al. [11] investigated the effect of bottom wind bracings on the structural performance of a bridge subjected to the Egyptian truck loading. The bridge model was a straight composite steel-concrete bridge. They concluded that wind bracings significantly increase both the flexural and torsional stiffness of such bridges when taken into account in design. Unfortunately, none of the bridge codes and specifications comments on the beneficial effect of the presence of the bottom lateral bracing on enhancing the structural performance in addition of being a resisting element to wind, [11]. Also, there is no research in the literature review regarding the influence of lateral bottom bracings on the behaviour of horizontally curved composite steel-concrete bridges.

The objective of the present study is concerned with the effect of the presence of bottom wind bracing on the behaviour of horizontally curved composite bridges. A 
careful numerical study is carried out by using the finite element method in the elastic range of loading. The present study considers the effect of type and arrangement patterns of lateral bottom bracings on tangential stresses, warping-to-bending stress ratio, vertical displacements, radial displacements and torsional angle of the bottom flanges of curved composite girder systems.

\section{FINITE ELEMENT ANALYSIS}

The finite-element modeling in the present study was carried out using the MARC/Mentat package [12], [13]. A three-dimensional finite element model with the following characteristics had been used: (1) a four-node thick shell element with six degrees of freedom at each node (element 75) was used to model the deck slab, steel webs and steel flanges; (2) the offset connection between the tops of the girders and the centre of the deck was modelled using beam elements (element 52). For curved beams, all geometry, boundary conditions and loading conditions were modelled in the cylindrical coordinate system. The shear connectors between concrete slab and steel flange were modelled by rigid beam elements with a large area but with low bending stiffness. Rigid connection beam elements were used to model the shear studs based on the assumption that no slip occurs between the concrete slab and the steel girder. This assumption is in agreement with experiments carried out by Thevendran et al. [1].

In present study, the following assumptions are considered: (1) the bridges are simply-supported; (2) the bridges have constant radii of curvature and uniform cross sectional area between support lines; (3) the effects of road super-elevation and curbs are ignored; (4) the reinforced concrete slab deck has complete composite action with the top steel flange of the I-girders; (5) all materials are elastic and homogenous; (6) webs of the steel girders are vertical, and (7) deformations are assumed to remain within the limits of small displacement theory. The accuracy of numerical results is verified via a comparison with experimental results by other researchers in an accompanying paper, [9]. A mesh with 4 elements for each flange, 8 elements for web and 40 shell elements along the span is found to be satisfactory for numerical investigation in predicting the elastic behavior of curved composite girder.

\section{BRIDGE GEOMETRY}

The bridge model used in this analysis is one of the existing and newly designed bridges in Egypt [14]. The basic model of the bridge consists of four steel girders, $2 \mathrm{~m}$ spacing between web centre-lines, and length of the bridge is $24 \mathrm{~m}$. The concrete deck is $8 \mathrm{~m}$ width and $25 \mathrm{~cm}$ thickness. The webs of the girders are $130 \times 1.3 \mathrm{~cm}$ and top and bottom flanges are $40 \times 4 \mathrm{~cm}$. The steel girders are provided with cross frames of $1 \mathrm{~L} 70 \times 70 \times 7$ spaced at intervals of $4 \mathrm{~m}$ for both straight and curved systems and modelled as beam elements. The cross frame members satisfy the requirement of slenderness ratio according to the Egyptian Code of Practice (ECP) for steel construction and bridges [15], where the maximum slenderness ratio $\left(\lambda_{\max }\right)$ for roadway bridge bracings in compression should not exceed 140 . Only bridges having $\mathrm{X}$-shaped cross diaphragms are considered in the current work. The depth of cross frames is 6 shell elements of the web height and each cross frame member is divided into 4 elements. Theoretically, it is recommended to extend the depth of cross frames all over the depth of the web but this is difficult in practice. Thus, the depth of cross 
frames is taken as 6 shell elements of web (not 8 elements) for conservative analysis. A cross section of the finite element model representing this bridge is shown in Fig. 1(a).

The material properties were: (a) steel: density, $\rho=7850 \mathrm{~kg} / \mathrm{m}^{3}$; yield stress, $\sigma_{y}=360 \mathrm{MPa}$; Young's modulus, $E=210 \mathrm{GPa}$; Poisson's ratio, $v=0.3$ and (b) concrete: density, $\rho=2500 \mathrm{~kg} / \mathrm{m}^{3}$; compressive strength, $30 \mathrm{MPa}$; Young's modulus, $E=25 \mathrm{GPa}$, Poisson's ratio, $v=0.2$. Three different span-to-radius of curvature ratios $(L / R)$ are considered; they are $0.1,0.3$ and 0.5 , i.e., the radii of curvatures are 240,80 and $48 \mathrm{~m}$, respectively. An isometric view of the finite element models is shown in Fig. 1(b). Each model consists of 5572 nodes and 5916 elements $(8$ elements for web and 4 elements for each flange and 48 shell elements along the span). One of the supports of the system is hinged (free to rotate about the radial direction) and the other is roller (free to rotate around the radial direction and to translate in the tangential direction).

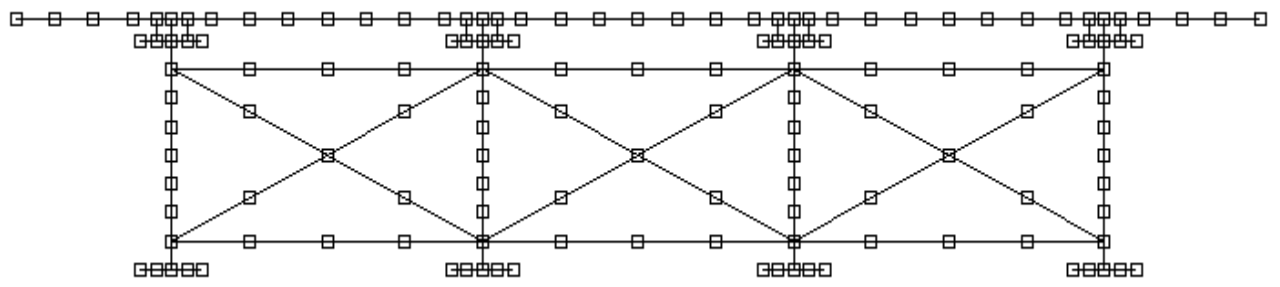

(a)

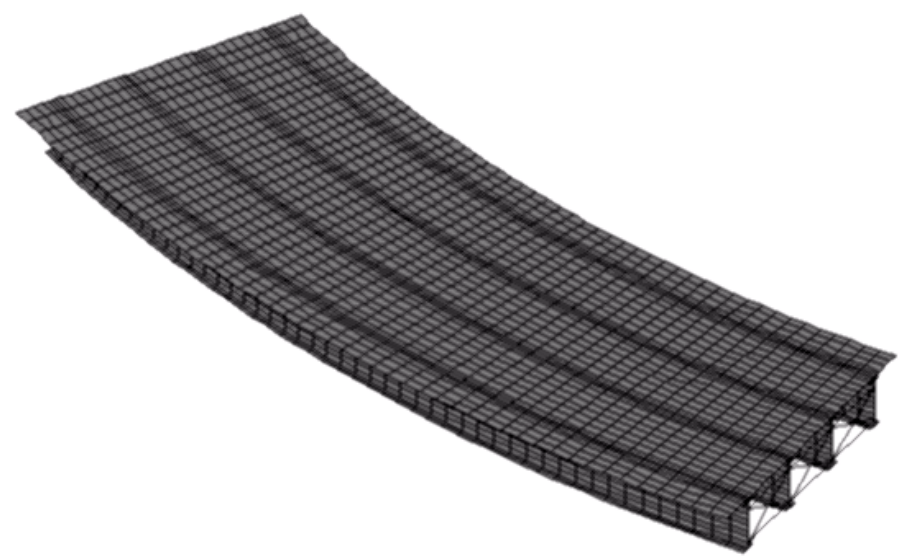

(b)

Figure 1: Bridge model: (a) finite element representation of bridge cross section; (b) isometric view of the bridge .

Shoring is assumed during the construction of the composite steel bridge so; all models are investigated under dead and live loads. The live load used in this investigation is the ECP [16]. ECP live load consists of: (1) main lane load of $3.0 \mathrm{~m}$ 
width which consists of $60 \mathrm{t}(600 \mathrm{kN})$ main truck in addition to leading and trailing uniform load of intensity $500 \mathrm{~kg} / \mathrm{m}^{2}\left(5 \mathrm{kN} / \mathrm{m}^{2}\right)$ on the rest of the lane area. The main lane must be positioned to give maximum straining actions in the bridge superstructure; (2) secondary lane load of $3.0 \mathrm{~m}$ width which consists of $30 \mathrm{t}(300 \mathrm{kN})$ secondary truck in addition to leading and trailing uniform load of intensity $300 \mathrm{~kg} / \mathrm{m}^{2}\left(3 \mathrm{kN} / \mathrm{m}^{2}\right)$ on the rest of the lane area; (3) the rest of the bridge carriage way is covered with a uniform load of intensity $300 \mathrm{~kg} / \mathrm{m}^{2}\left(3 \mathrm{kN} / \mathrm{m}^{2}\right)$. The dynamic load factor " $\boldsymbol{I}$ " is calculated using the following roadway bridge impact formula " $\boldsymbol{I}=\mathbf{0 . 4 - 0 . 0 0 8} \boldsymbol{L}$ "; where $L$ is the beam span length in m. Only the main lane load (truck + uniform) is to be magnified by the impact (dynamic) factor, neither the secondary lane load nor the uniform load is to be magnified. The impact factor for $L=24 \mathrm{~m}$ is 0.208 . Figure 2 shows the load case for maximum live load bending moment of a straight system of girders including impact.

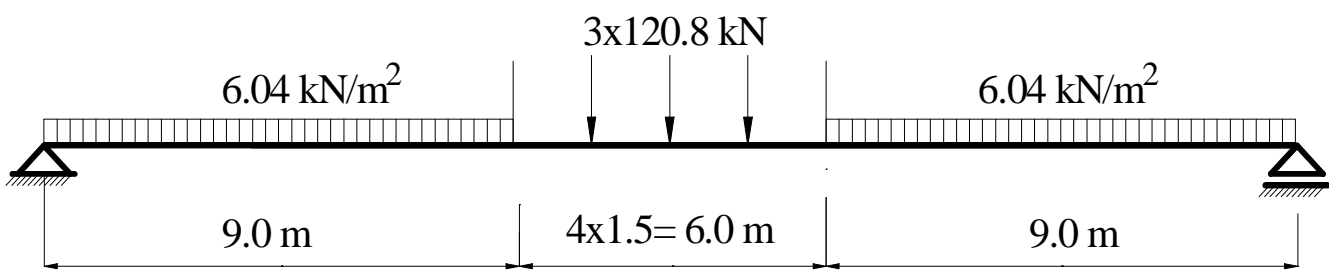

(a)

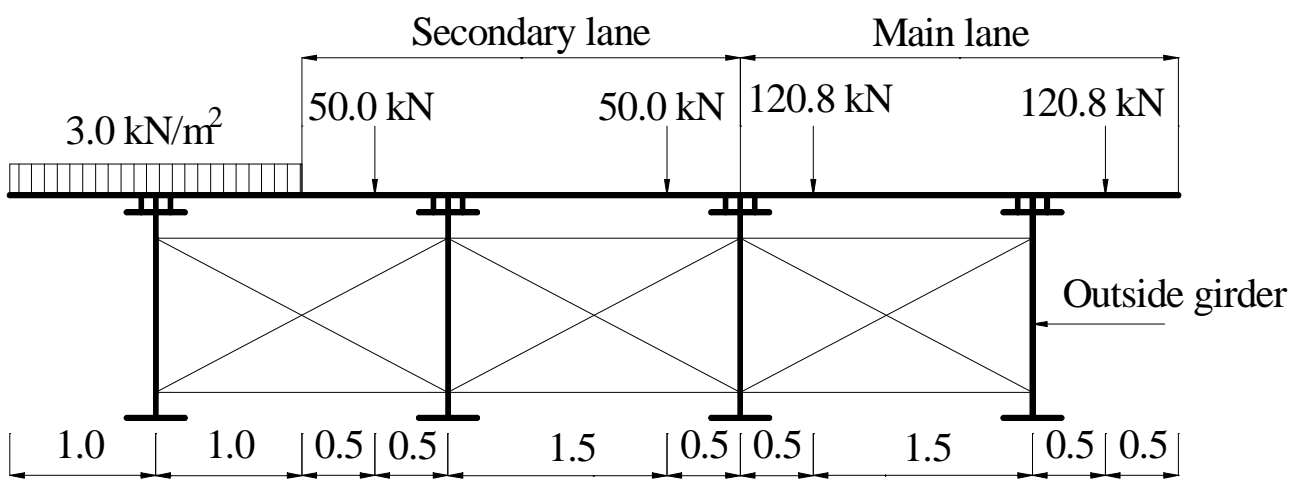

(b)

Figure 2: Bridge live load: (a) longitudinal cross section in the main lane for maximum bending moment; (b) lateral cross section at mid span

\section{NUMERICAL ANALYSIS}

A large number of finite element models were constructed, and normalizing techniques were used to help generalize the results. For instance, the study is interested in the effects that the addition of lateral bracing system has over the results obtained using cross frames only taking into consideration the degree of curvature. So, the major axis (vertical) bending stresses resulting from the curved system were normalized to 
the bending stresses of the straight system with the same length and cross section dimensions. For the sake of comparison study, the length of the outside girder of the curved system is taken the same as that of the straight system $(24 \mathrm{~m})$ and the addition of other girders is on the inside of curvature to preserve a constant length and radius of curvature for the critical outside girder. On the other hand, since significant warping stresses are not generally present in straight systems, the warping stress at the edge of the flange is generally normalized to the maximum tangential bending stress of the girder and referred to as the warping-to-bending stress ratio. Indeed, warping-tobending stress ratio $F_{w b}$, is an important issue in preliminary design purposes so that the American Association of State Highway and Transportation Officials (AASHTO) [17] mandates the $F_{w b}$ to be $\leq 0.50$.

The present study considers the effect of type and arrangement patterns of lateral bottom bracings on tangential stresses, warping-to-bending stress ratio, vertical displacements and radial displacements through the inner edge, middle and outer edge of the bottom flange along the span of the critical outside girder. Figure 3 shows the six different bridge bracing configurations which are investigated in this study, namely: i) no horizontal bracing (Type 0); (ii) single-diagonal bracings in all bays (Type 1); (iii) $\mathrm{X}$ - bracings in all bays (Type 2); (iv) X-bracings in outer bays only (Type 3); (v) Xbracings in end and middle panels (Type 4); (vi) X-bracings in end panels only (Type 5). The cross section of lateral bracings are considered $1 \mathrm{~L} 120 \times 120 \times 12$ for

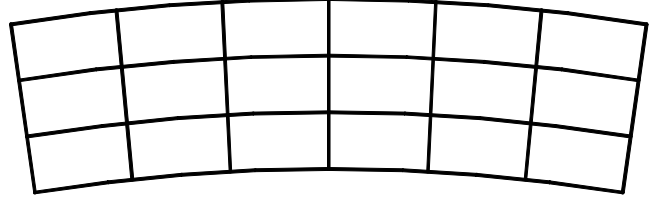

(a) Type 0

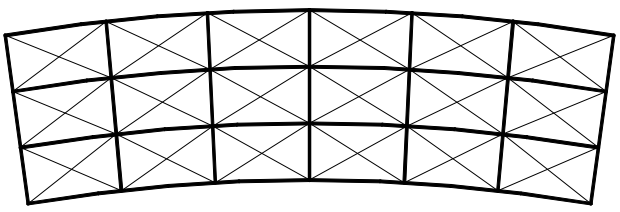

(c) Type 2

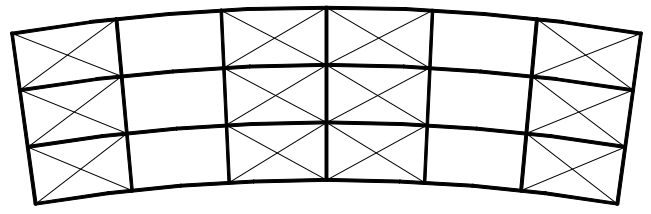

(e) Type 4

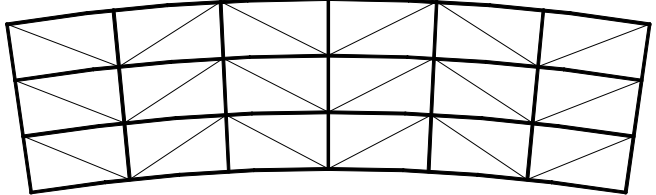

(b) Type 1

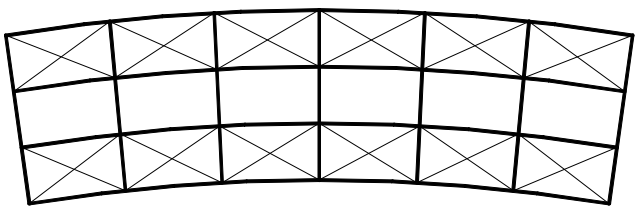

(d) Type 3

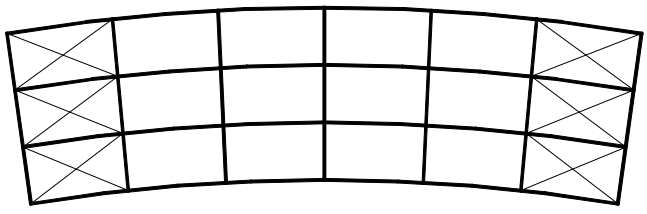

(f) Type 5

Figure 3: Arrangement patterns of bridge lateral bottom bracings: (a) no lateral bracings; (b) single diagonal member in all bays; (c) X-bracings in all bays; (d) X-bracings in outer bays; (e) X-bracings in end and middle panels; (f) X-bracings in end panels only. 
$\mathrm{X}$-type bracings and $1 \mathrm{~L} 160 \times 160 \times 15$ for single diagonal bracings so as to keep the maximum slenderness ratio to be 140. It is important to mention that the cross sectional area of single diagonal bracings is nearly twice that of the $\mathrm{X}$-type bracings.

\section{RESULTS AND DISCUSSIONS}

For all models, tangential stresses, vertical and radial displacements at outer edge, middle and inner edge of the bottom flange of the outside girder are calculated with the physical and mechanical properties mentioned above. The warping stress is estimated as one half of the difference between the outer and inner edge stresses. The warping-to-bending stress ratio is calculated by dividing the warping stress to the maximum tangential stress at the middle of the bottom flange at the critical section. The following description summarizes the results.

\subsection{Bending Stresses}

Figure 4 shows the effect of bottom lateral bracings on bending stresses of curved composite girders for different span-to-radius of curvature ratios. The values obtained for curved system are normalized to that of straight system of the same length and cross section dimensions. So, a stress ratio of curved to straight system, $F_{c s}=1.0$ would represent a curved system with the same response as that of the comparable straight system. From Fig. 4, it is shown that the existence of lateral bracings decreases the bending stresses of the curved girders for all arrangement patterns (Type 1 to Type 5 ). It is clear that the basic type which is not reinforced with lateral bracings (Type 0) has the maximum ratio of stresses. However, Type 2 which consists of X-bracings in all bays has the smallest stress ratio. The reduction in stress ratio may exceed $25 \%$ of the stresses obtained using cross frames only. Also, it is shown that Type 3 at which the system is reinforced longitudinally with $\mathrm{X}$-bracings in outer bays only gives smaller stress ratio than that of Type 4 which consists of the same number of bracing members but with different pattern. Furthermore, Type 5 which consists of X-bracings in end panels only gives the greatest stress ratio of the studied reinforcement patterns, so it is not so useful for curved system design.

Lateral bracings in curved systems reduce the bending stresses significantly unlike using cross frames only which does not affect the bending stresses, [8]-[9]. This is due to the fact that the existence of lateral bracings near bottom flanges in addition to the existence of the deck slab at the top flanges forms quasi-closed box-girders and consequently increases the flexural stiffness of curved composite girders which in turn reduces bending stresses. From Fig. 4, it is shown that Type 2 is the most effective pattern of lateral bracings, especially for small radii of curvatures. It is important to mention that for Type 2 of lateral bracings, the stress ratio is almost the same for all radii of curvatures. On the other hand, although Type 1 (single diagonal system of bracings) gives a reduced bending stress ratio, the cross sectional area of members is nearly twice that of the X-type bracings to satisfy the maximum slenderness ratio of bracings to be 140 . So, using single diagonal bracing pattern does not save a lot of materials than the X-bracings pattern. Thus, Type 3 which consists of X-type bracings in outer bays only is preferable to Type 1 of single diagonal bracings in all bays. 


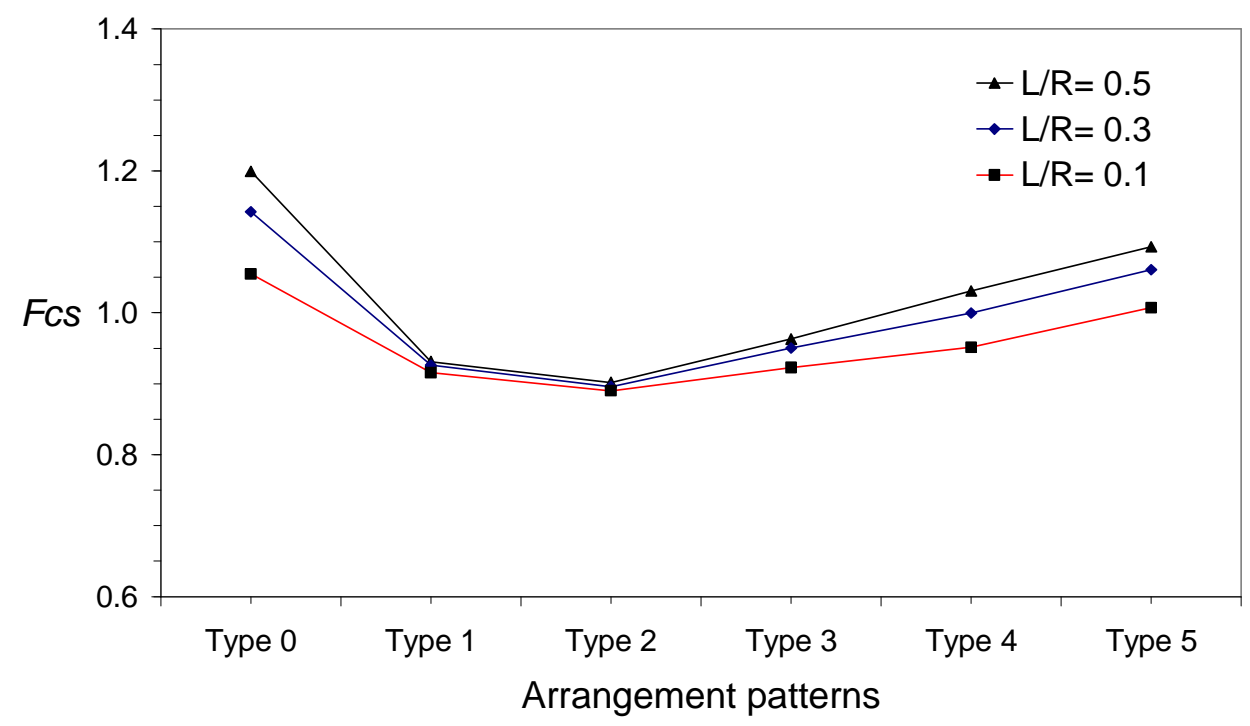

Figure 4: Effect of lateral bracings on bending stresses .

\subsection{Warping-To-Bending Stress Ratio}

Figure 5 shows the warping-to-bending stress ratio $F_{w b}$ along the span of the outside girder of a curved bridge system for span-to-radius of curvature ratio, $L / R=0.5$ for two arrangement patterns of bottom lateral bracings in addition to Type 0 for which there is no lateral bracings. From Fig. 5, it can be derived that at the cross frame locations, the maximum tensile stresses are at the outer edge of flange and the minimum tensile stresses are at the inner edge of the flange. However, in the intervals between cross frames, the direction of the bimoment is reversed and the highest stresses occur on the inside edge of the flanges so the sign of the $F_{w b}$ is negative. This is in agreement with the results obtained by Davidson et al. [8]. On the other hand, it is shown that the existence of lateral bracings improves the behaviour of curved composite girders and stabilizes the warping-to-bending stress ratio, $F_{w b}$ i.e., it decreases the maximum warping-to-bending stress ratio and equalizes the positive and negative ratios. It is interesting to mention that the figure is not symmetric due to the unsymmetrical boundary conditions at the end supports of the girder.

Figure 6 shows the relationship between warping-to-bending stress ratio, $F_{w b}$ and different arrangement patterns of bottom lateral bracings for different span-toradius of curvature ratios. It is shown that the existence of lateral bracings has a small effect on warping-to-bending ratio for small degrees of curvatures but it has a considerable effect for high degree of curvature $(L / R=0.5)$. Indeed, the $F_{w b}$ for all types of bracings is less than that of Type 0, where there is no lateral bracings. Since the bending stresses are decreased for all types of bracings (as discussed above), then the reduction in $F_{w b}$ means that the warping stresses are decreased with larger percentages than that in bending stresses as shown for Type 1- Type 3. However, because $F_{w b}$ for Type 4 and Type 5 are almost the same as Type 0 , then the reduction in warping 
stresses in these two types is less than that in bending stresses. So, warping stresses are decreased for all types of lateral bracings. This is interpreted by the fact that the presence of lateral bracings increases the torsional stiffness of such curved composite bridges. It is also clear that Type 2 which consists of X-bracings in all bays has the smallest warping-to-bending stress ratio, $F_{w b}$ and consequently has the greatest reduction in warping stresses while Type 5 has the smallest reduction in warping stresses.

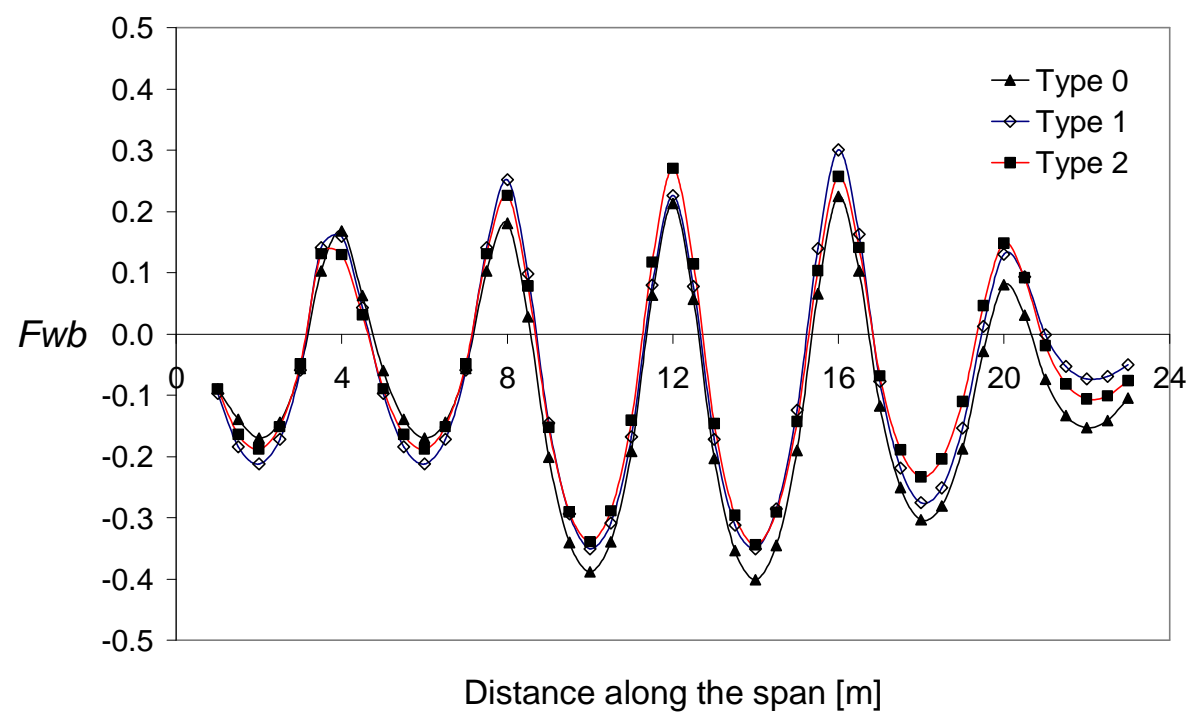

Figure 5: Warping-to-bending stress ratio $\left(F_{w b}\right)$ along the span of the outside girder $(L / R=0.5)$.

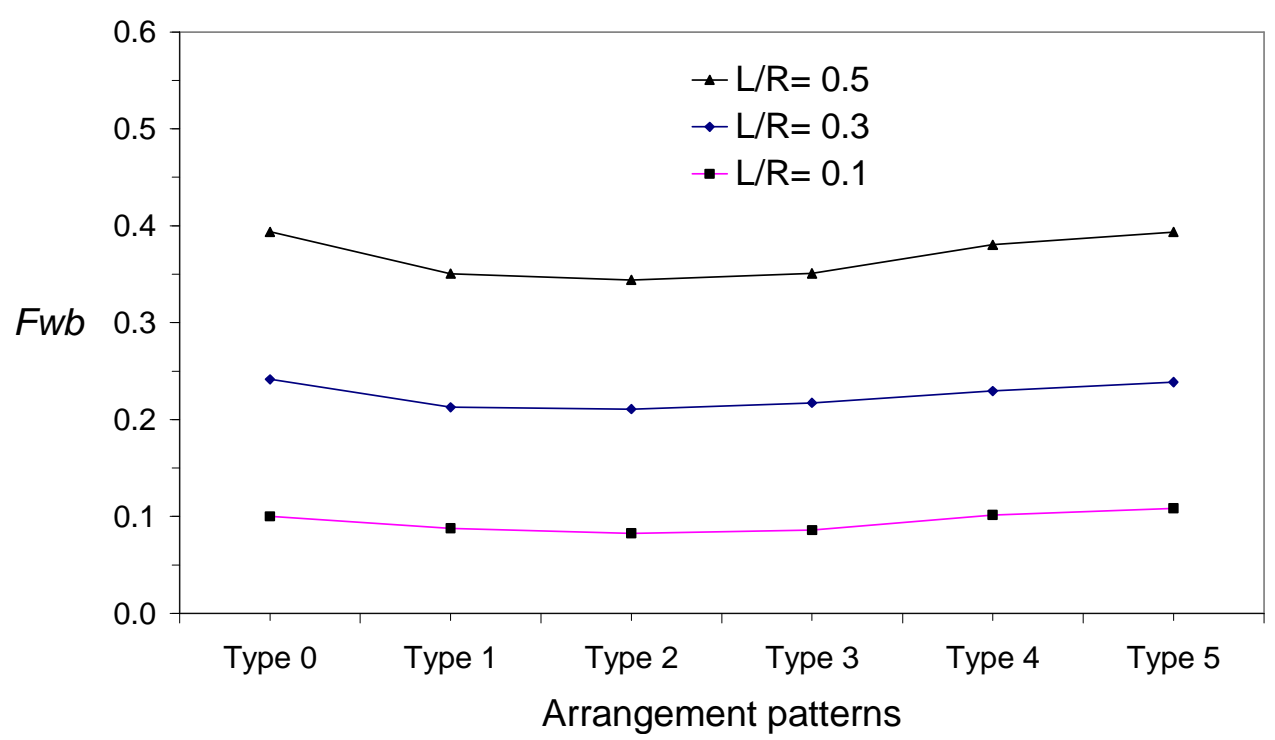

Figure 6: Effect of lateral bracings on warping-to-bending stress ratio. 


\subsection{Vertical Displacements}

Figure 7 plots the normalized vertical displacements at the middle of bottom flanges of curved systems versus different arrangement patterns of lateral bracings for different span-to-radius of curvature ratios. A displacement ratio of curved to straight system, $\Delta \mathrm{c} / \Delta \mathrm{s}=1.0$ would represent a curved system with the same response as that of the comparable straight system with the same length and cross section dimensions. From Fig. 7, it is shown that the existence of lateral bracings decreases the vertical displacements of the curved girders for all patterns of lateral bracings (Type 1 to Type 5). This is due to the increase of both flexural and torsional stiffnesses of the bridge. It is also shown that the basic type which has no lateral bracings and has cross frames only (Type 0) has the greatest vertical displacements.

From Fig. 7, it can be observed that all types of lateral bracings have approximately the same influence on the vertical displacements for low degrees of curvatures $(L / R=0.1, L / R=0.3)$. However, the effect of lateral bracings is different from one to another for high degree of curvature $(L / R=0.5)$. Also, it is easily seen that Type 2 at which the girders are reinforced with X-bracings in all bays has the smallest displacement ratio. On the other hand, it is shown that Type 3 at which the system is reinforced with X-bracings in outer bays only provides smaller displacement ratio than Type 4 at which the system is reinforced with the same number of bracing members but with different pattern. Furthermore, Type 5 which consists of X-bracings in end panels only gives the greatest displacement ratio of the studied reinforced systems. Indeed, this reassures the observation that Type 5 of lateral bracings is not so useful for curved system design.

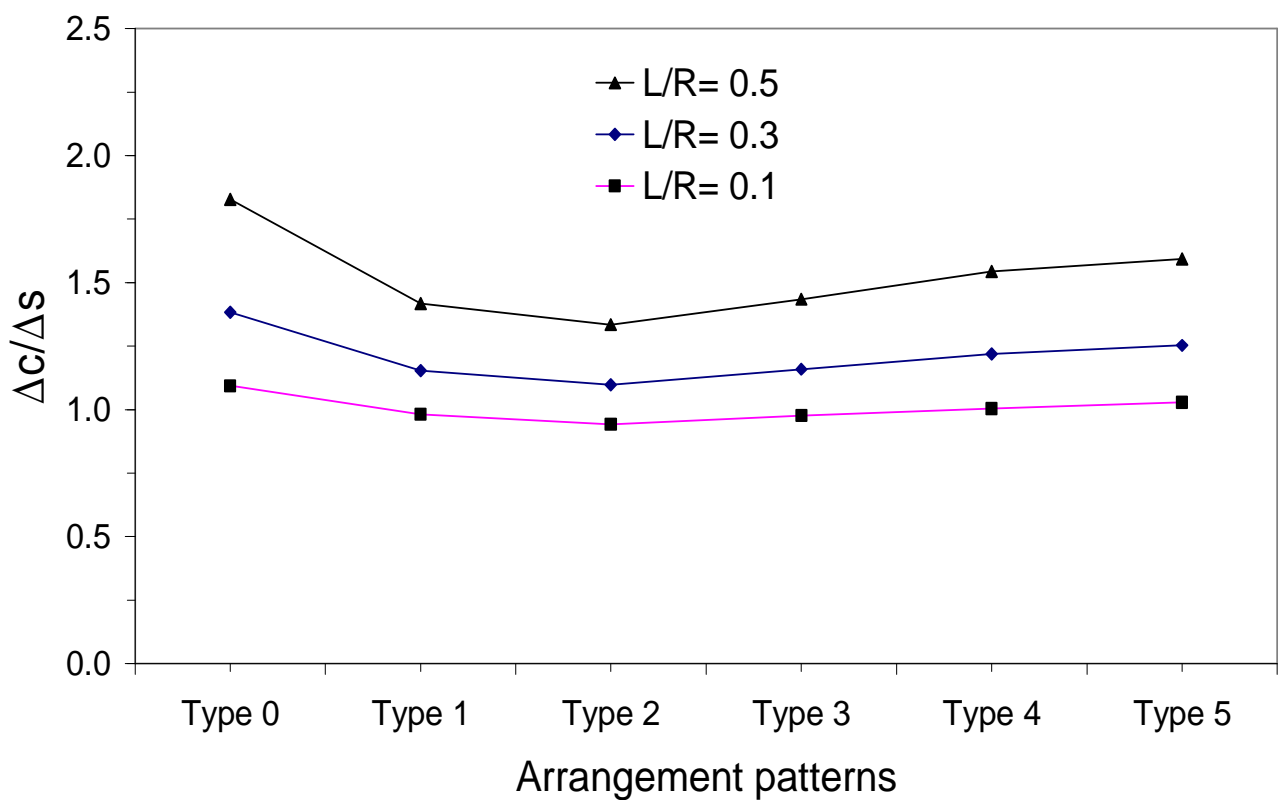

Figure 7: Effect of lateral bracings on vertical displacement. 


\subsection{Torsional Angle}

It is found that the vertical displacements of bottom flanges of curved girders vary from the inner to the outer edges of the flange. The vertical displacements of outer edges are greater than that of the inner edges as shown in Fig. 8. This in agreement with the results obtained by Yoo and Littrell [7] and Davidson et al. [8]. To take the outer and inner vertical displacements into account, the effect of lateral bracings on the torsional angle of the bottom flange of the outer girder is studied. The torsional angle is calculated in radians for all types of lateral bracings. The torsional angle is the angle which its sine is the difference between vertical displacements at outer and inner edges divided by the bottom flange width.

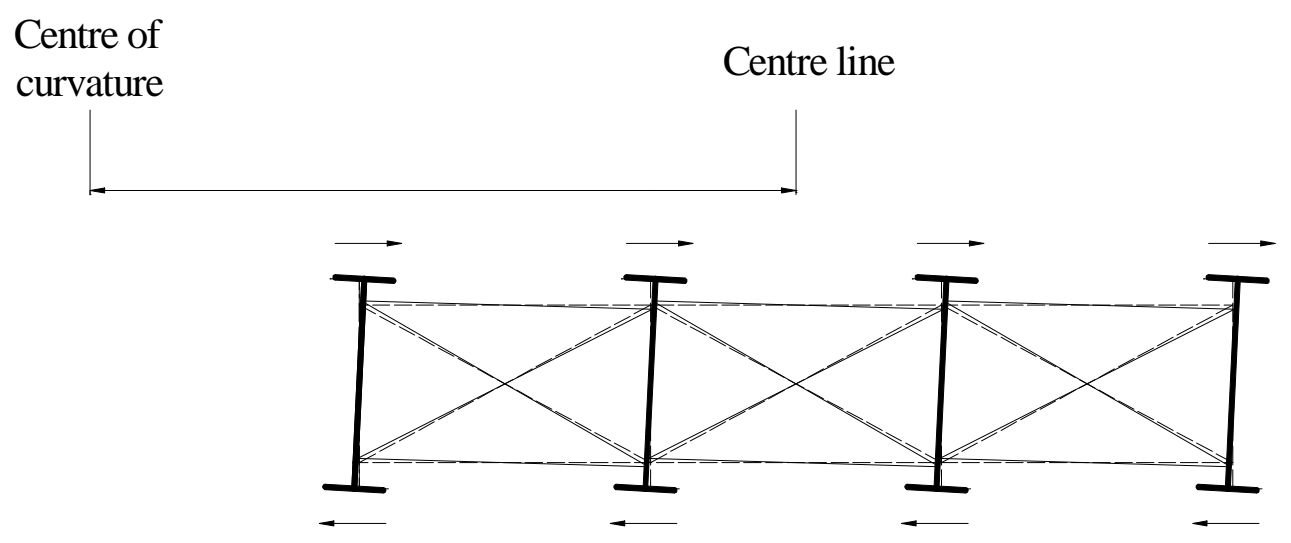

Figure 8: Effect of curvature on displacements of main girders in positive vertical bending region.

Figure 9 illustrates the torsional angles of bottom flange versus different types of lateral bracings for different span-to-radius of curvature ratios. From Fig. 9, it is shown that the basic type which is not reinforced with lateral bracings (Type 0) has the maximum torsional angle. However, the existence of lateral bracings stabilizes the vertical displacements of outer and inner edges and decreases the torsional angle of bottom flange of the curved girder for all types of lateral bracings (Type 1 to Type 5). Again, Type 2 which consists of X-bracings in all bays gives the smallest torsional angle among the studied patterns of lateral bracings. It is important to mention that the influence of lateral bracings is slight for low degree of curvature $(L / R=0.1)$ but is significant in high degree of curvature $(L / R=0.5)$.

\subsection{Radial Displacements}

Figure 10 plots the normalized radial displacements at the middle of bottom flange of the outer girder of curved bridges versus different arrangement patterns of lateral bracings for different span-to-radius of curvature ratios. The values obtained for curved girders were normalized to that of the corresponding straight system of the same length and cross section dimensions. From Fig. 10, it is shown that the existence of lateral bracings decreases the radial displacements of the curved girders for all types 
of lateral bracings (Type 1 to Type 5). This is due to the increase of flexural stiffness of the bridge. However, the basic type which is not reinforced with lateral bracings (Type 0 ) has the maximum ratio of radial displacements. It is of interest to mention that the normalized values of radial displacements have greater values than that in Fig. 7 for vertical displacements. This is due to the small value of radial displacement of straight girder which is due to the live load eccentricity. Also, it is important to mention that the radial displacements for both straight and curved girders are negative i.e., the displacements are towards the centre of curvature.

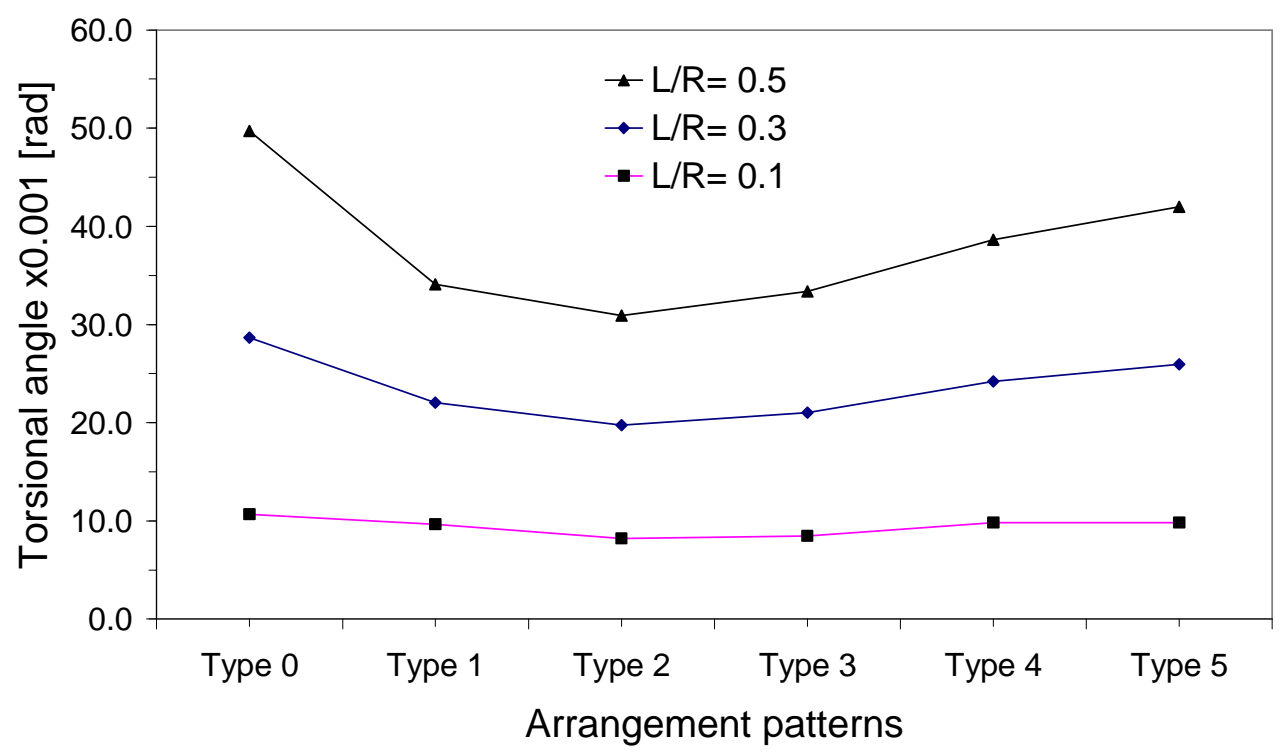

Figure 9: Effect of lateral bracings on torsional angle.

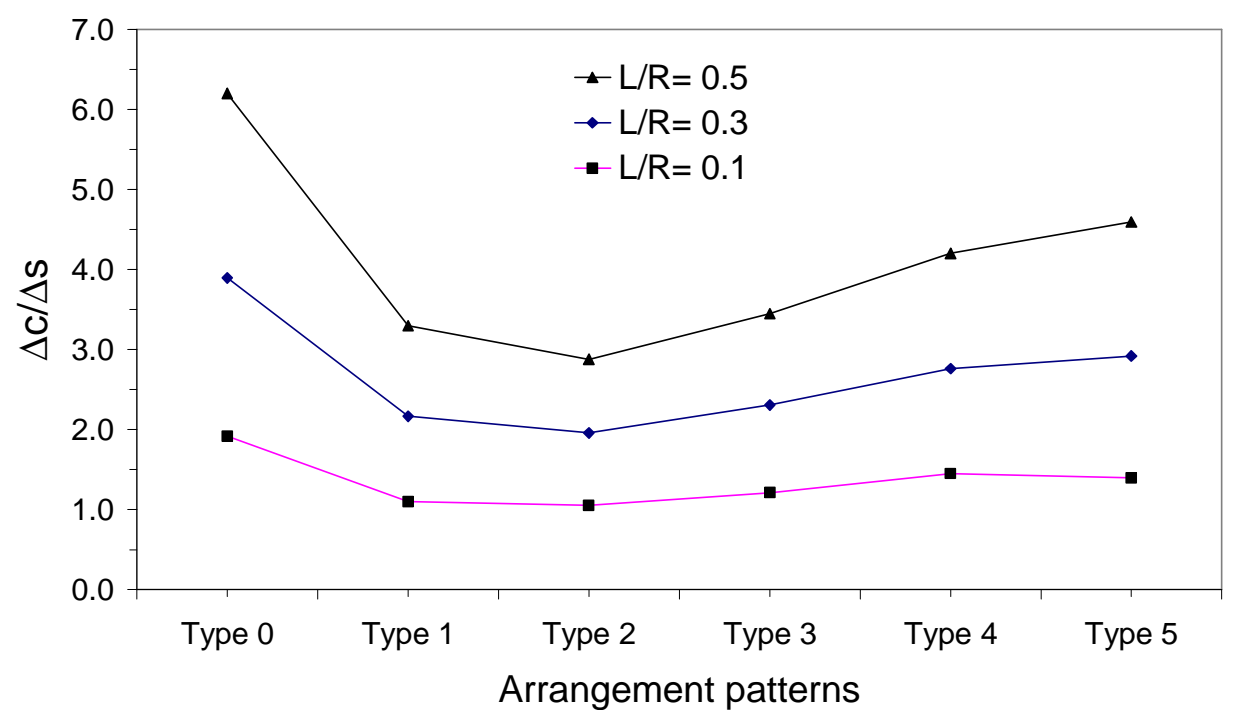

Figure 10: Effect of lateral bracings on radial displacement . 
All types of lateral bracings have approximately the same influence on the vertical displacements for low degree of curvature $(L / R=0.1)$. However, the effect of lateral bracings is different from one to another for high degrees of curvatures $(L / R=0.3$, $L / R=0.5$ ). It is also clear that Type 2 at which the system is reinforced with $\mathrm{X}$-bracings in all bays has the smallest displacement ratio. Also, it is shown that Type 3 at which the system is reinforced with $\mathrm{X}$-bracings in outer bays only provides smaller displacement ratio than Type 4 which consists of the same number of bracing members but with different pattern. Furthermore, Type 5 at which the system is reinforced with $\mathrm{X}$-bracings in end panels only gives the greatest displacement ratio of the reinforced systems. The results are similar to that obtained for torsional angles of bottom flanges.

\subsection{Forces In Bracing Members}

To determine the effect of curvature on the forces of bracing members, the forces in bracing members for Type 2 which consists of X-bracings in all bays are estimated with varying curvatures. Indeed, Type 2 is chosen since it is the most effective type of lateral bracing for curved composite systems. It is found that the maximum forces occur in the outmost bay of the bridge. This is due to the fact that external outer girders have large length and consequently large bending moment. Also, it is found that the values of axial forces in bottom bracing members are not symmetrical in plan because of different boundary conditions at the ends (one end is hinged while the other is roller).

Figure 11 plots the maximum axial forces in bottom bracing members for different degrees of curvatures for the outmost bay using Type 2 of lateral bracings. It is found that the maximum forces occur in the first and second panels near the hinged support of the curved girder system. From Fig. 11, it is shown that the maximum forces in bracing members increase with high degree of curvature and vice versa. Also, it is

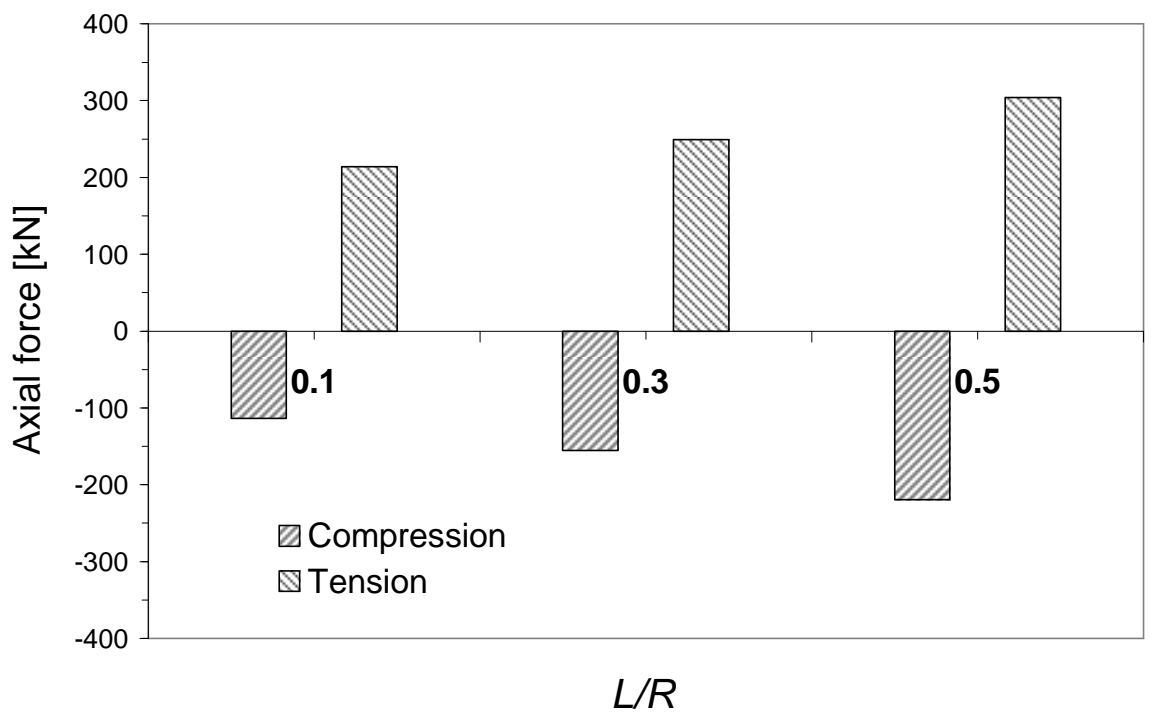

Figure 11: Maximum axial forces in bottom bracings in outmost bay members for Type 2. 
found that the maximum compression force occurs in the first panel near the hinged support. However, the maximum tension force occurs in the second panel from the hinged support. It can be concluded that for high degree of curvature, the stresses in bracing members should be checked since they are subjected to large stresses due to curvature in addition to those due to wind loads.

\section{CONCLUSIONS}

The present study is concerned with the effect of the presence of bottom lateral bracing systems on the behaviour of horizontally curved composite girders in the elastic range of loading. A careful numerical study is carried out by using the finite element method to analyze the behaviour of composite girders curved in plan. The accuracy of numerical results is verified via a comparison with experimental results obtained by other researchers in an accompanying paper, [9]. Shoring is assumed to be used during construction and live loads according to ECP are used in the analysis. The present study considers the effect of type and arrangement patterns of lateral bottom bracings on tangential stresses, warping-to-bending stress ratio, vertical displacements and radial displacements on the response of the curved composite girder bridges provided with cross frames. Also, the maximum axial forces in bracing members for the most effective type are carefully studied.

Based on the numerical results, the following conclusions can be drawn:

(1) The presence of bottom lateral bracings in curved composite bridge forms quasiclosed box-girders and consequently increases both bending and torsional stiffnesses of the bridge. This results in significant reduction of both bending and warping stresses. The reduction in stresses of curved bridges is more pronounced for high degrees of curvatures and may exceed $25 \%$ of that obtained using cross frames only. So, lateral bracings can be used effectively in strengthening of existing bridges or to decrease the cross sectional area of new curved composite bridges.

(2) The existence of lateral bracings decreases both vertical and radial displacements of curved girders for all types of lateral bracings. Also, it decreases the torsional angle of the bottom flange. Again, the influence of lateral bracings is more pronounced in curved bridges with small radii of curvatures.

(3) The most effective pattern of lateral bracings is Type 2 which consists of Xbracings in all bays, since it gives the maximum reduction in both stresses and displacements of curved bridges. However, curved composite bridges which are reinforced with X-bracings in end panels only has the greatest stresses and displacements of the studied bridge models, so it is not so useful for curved system design.

(4) The maximum forces in bracing members occur in the outmost bays and increase with high degree of curvature and vice versa. Thus, for high degree of curvature, the stresses in bracing members are high and should be checked since the bracing members are subjected to stresses due to curvature in addition to those due to wind loads. 


\section{REFERENCES}

[1] Thevendran, V., Shanmugam, N. E., Chen, S. and Richard-Liew, J. Y.: "EXPERIMENTAL STUDY ON STEEL-CONCRETE COMPOSITE BEAMS CURVED IN PLAN", J. Engineering Structures, Vol. 22, pp. 877-889, (2000).

[2] Xanthakos, P. P.: "THEORY AND DESIGN OF BRIDGES", John Wiley and Sons, Inc., Chapter 12, 1443 pp., (1994).

[3] Thevendran, V., Chen, S., Shanmugam, N. E., and Richard-Liew, J. Y.: "NONLINEAR ANALYSIS OF STEEL-CONCRETE COMPOSITE BEAMS CURVED IN PLAN", J. Finite Elements in Analysis and Design, Vol. 32, pp. 125-139, (1999).

[4] Salem, A.H., El-Aghoury, M. and Moustafa, T. S.: "FINITE ELEMENT MODELING OF COMPOSITE STEEL-FREE DECK BRIDGES CURVED VERSUS STRAIGHT BRIDGES", International Colloquium on Structural and Geotechnical Engineering, $11^{\text {th }}$ ICSGE, Cairo, Egypt, 17-19 May (2005).

[5] Schelling, D., Namini, A. H. and Fu, C. C.: "Construction effects ON BRACING ON CURVED I GIRDERS”, J. Structural Engineering, ASCE, 115(9), pp. 2145-2165, (1989).

[6] Heins, C. P. and Jin, J. O.: "LIVE LOAD DiSTRIBUTION ON BRACED CURVED I- GIRDERS", J. Structural Engineering, ASCE, 110(3), pp. 523-530, (1984).

[7] Yoo, C. H., and Littrell, P. C.: "CROSS-BRACING EFFECTS IN CURVED STRINGER BRIDGES", J. Structural Engineering, ASCE, 112(9), pp. 2127-2140, (1986).

[8] Davidson, J.S., Keller, M.A. and Yoo, C.H.: "Cross-Frame SpaCing AND PARAMETRIC EFFECTS IN HORIZONTALly CURVED I-GIRDER BRIDGES", J. Structural Engineering, ASCE, 122(9), pp. 1089-1096, (1996).

[9] Abdo, M. A.-B. and Abo El-Wafa, W.: "PARAMETRIC STUDY OF THE EFFECT OF CROSS-FRAMES ON THE BEHAVIOUR OF COMPOSITE STEEL-CONCRETE GIRDERS CURVED IN PLAN AND CONSTRUCTED WITH SHORING", J. Engineering Sciences, Faculty of Engineering, University of Assiut, 34(5), (2006).

[10] Hirasawa, H., Hayashikawa, T. and Sato K.: "LOADING TESTS AND ANALYSIS OF CURVED TWO-GIRDER BRIDGES WITH LATERAL BRACINGS", The Eighth East Asia-Pacific Conference on Structural Engineering and Construction, Nanyang Technological University, Singapore, Paper no. 1135, (2001).

[11] El-Mezaini, N., Mahmoud, Z., and Sennah, K.: "COMPOSITE CONCRETE-STEEL I-GIRDER BRIDGE EVALUATION USING FINITE-ELEMENT ANALYSIS APPROACH", International Conference on Structural \& Geotechnical Engineering and Construction Technology IC-SGECT'04, Mansoura, Egypt, Paper no. 128, (2004).

[12] MARC Analysis Research Corporation, Volumes; A, B, and C, Version 2001, (2001).

[13] MARC Analysis Research Corporation, Mentat User's Guide, Version 2001, (2001).

[14] Nasr, A. M., Amer, A. H., Saleh, M. M. and AbuHamd M. H.: "SimPlified LOAD DISTRIBUTION FACTORS FOR CURVED STEEL I-GIRDER BRIDGES BASED ON ECP LIVE LOADS", Eleventh International Colloquium on Structural and Geotechnical Engineering, $11^{\text {th }}$ ICSGE, Cairo, Egypt,17-19 May (2005).

[15] EGYPTIAN CODE OF PRACTICE FOR STEEL CONSTRUCTION AND BRIDGES (ECP), Code No. (205), 255 pp., (2001). 
[16] EGYPTIAN CODE FOR FORCE AND LOAD COMPUTATION IN STRUCTURES AND BUILDINGS (ECP), 76 pp., (2003).

[17] American Association for State Highway and Transportation Officials, (AASHTO): "GUIDE SPECIFICATION FOR HORIZONTALLY CURVED HIGHWAY BRIDGES”, Washington, D.C., (1996).

\section{تأثير أنظمة السند العرضية السفلية على سلوك الكبارى المركبة من الصلب

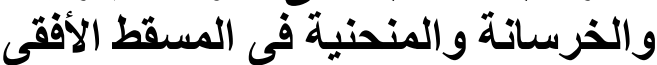

تستخدم الكمرات المركبة من الصلب والخرسانة والمنحنية فى المسقط الأفقى كثيراً

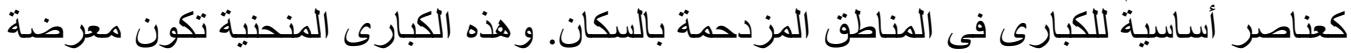

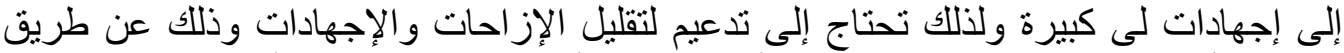
استخدام أحجبة (Cross frames) فقط أو باستخدام أحجبة بالإضافة إلى ألى ألظمة سند عرضية (Lateral bracing systems)

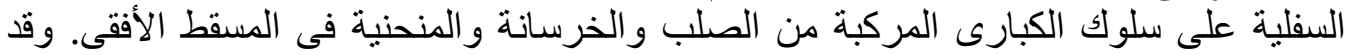
استخدمت فى هذا البحت طريقة العناصر المحددة كطريقة عددية وذللك فى مدى التحميل المرن.

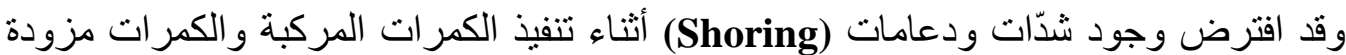
بأحجبة. هذا ويشمل البحث در اسة كل من الإجهادات المماسية (Tangential stresses) ،

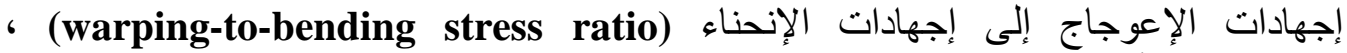
الإزاحات الرأسية وكذلك الإزاحات القطرية خلال (داخل ووسط وخارج) الثفة الإلفاتلية و المعرضة للثد وذلك بطول الكمرة الخارجية الحرجة من النظام الإنشائى. وقد تم كذلك دراسة أقصى قوى ناتجة بعناصر السند العرضية للنظام الأمثل للسند.

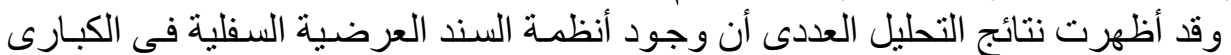

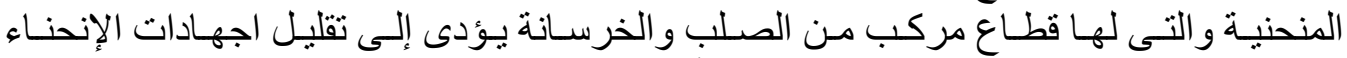

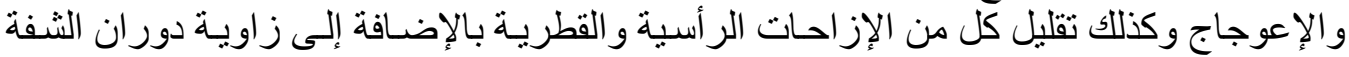

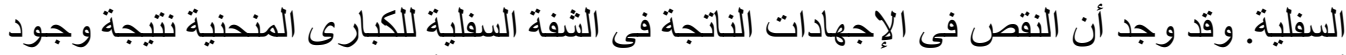

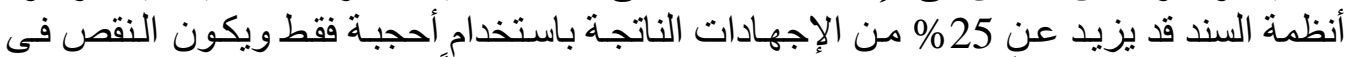

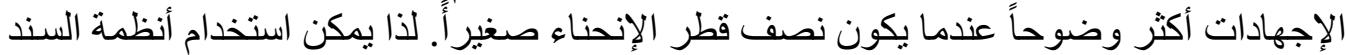

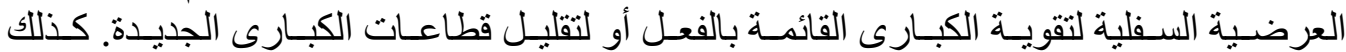

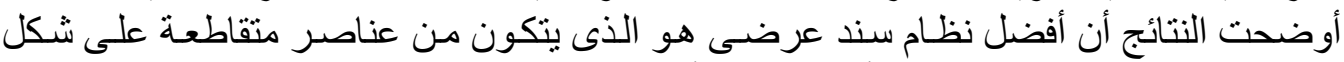

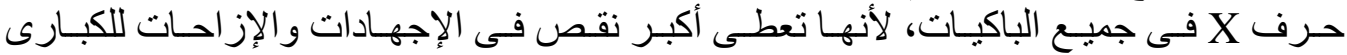

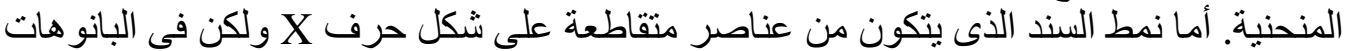

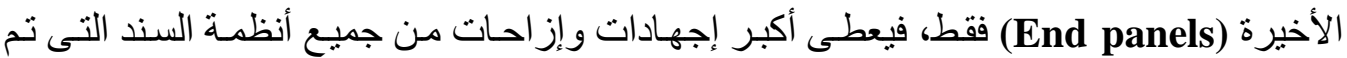

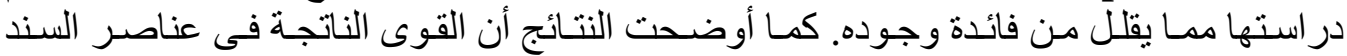

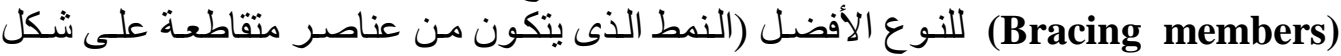

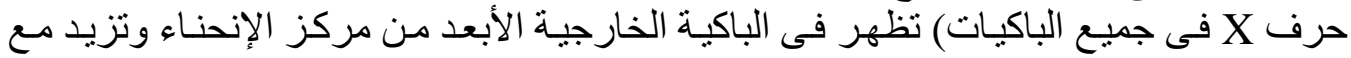

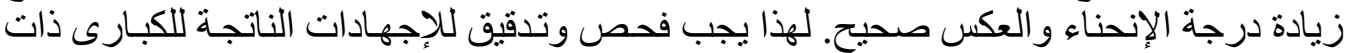

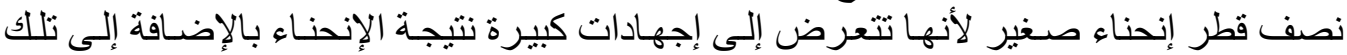

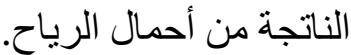

